\title{
Model matematyczny bilansu energetycznego okien w budynkach mieszkalnych
}

\author{
Joanna Borowska, Walery Jezierski \\ Zaktad Podstaw Budownictwa i Fizyki Budowli, \\ Wydziat Budownictwa i Inżynierii Środowiska, Politechnika Białostocka, \\ e-mail: j.borowska@doktoranci.pb.edu.pl,w.jezierski@pb.edu.pl
}

Streszczenie: W prezentowanym artykule przedstawiony został opracowany przez autorów model matematyczny służący do określenia bilansu energetycznego stolarki okiennej w budynkach mieszkalnych. Przedstawiono algorytm obliczania strat i zysków ciepła przez okno, tj. składników bilansu cieplnego okna, a także tok postępowania przy wyborze zmiennych parametrów, wchodzących w model matematyczny oraz nadających się do optymalizacji rozwiązań stolarki okiennej: powierzchni okna, współczynników przenikania ciepła $U$ dla szyby i ramy okiennej, współczynnika przepuszczalności $g$ i innych. Zaproponowano również program eksperymentu obliczeniowego.

Słowa kluczowe: bilans energetyczny, stolarka okienna, model matematyczny.

\section{Wprowadzenie}

Obecnie stale dąży się do znalezienia takich rozwiązań architektonicznobudowlanych, które pozwolą na zmniejszanie kosztów ponoszonych na zapotrzebowanie budynku na energię. Takowe zabiegi mogą dotyczyć nowoprojektowanych budynków jak i tych poddawanych termomodernizacji. Wydaje się, że bardziej opłacalne mogłoby być poprawne zaprojektowanie przegród budynku w taki sposób, by racjonalizować koszty jego utrzymania jeszcze zanim zostanie on wzniesiony niż wprowadzać w nim zmiany już po jakimś czasie. By tak mogło być, trzeba określić odpowiednie wymiary przegród oraz otworów, a także materiały do ich wykonania w taki sposób, aby osiągnąć jak najbardziej korzystne parametry izolacyjności [1]. Jednak, aby temu sprostać, należy zoptymalizować parametry analizowanych elementów budynku, czego wynikiem będą wiarygodne obliczenia ukazujące jak powinny być ukształtowane oraz wykonane przegrody.

By móc mówić o optymalizacji parametrów okien, należy określić bilans energetyczny dla wycinka kompleksowej przegrody wraz z otworem okiennym, czyli zsumować straty i zyski dla takiego przypadku. Najlepiej, gdyby bilans energetyczny miał ujemny znak, wówczas zyski ciepła przewyższą straty i analizowany wycinek przegrody będzie więcej energii dawał dla budynku niż przez niego tracił. W przeciwnym wypadku (gdyby suma strat i zysków była dodatnia) dążymy do uzyskania jak najmniej dodatniego wyniku, gdyż po to dobiera się odpowiednie wskaźniki i współczynniki, a także zakresy ich zmienności, aby uzyskać pożądaną (minimalną) wartość bilansu cieplnego.

W związku z tym, że już kilkoro badaczy [2,3] podjęło się prób optymalizowania parametrów okien i nie zawsze były to próby poprawnie wykonane, zaistniała potrzeba przeprowadzenia badań raz jeszcze, lecz pod innym kątem i z zastosowaniem innych metod. W niniejszym artykule przedstawiono algorytm obliczania bilansu cieplnego stolarki okiennej oraz program eksperymentu obliczeniowego, na podstawie wyników, z którego będę tworzone modele matematyczne bilansu dla optymalizacji parametrów stolarki okien- 
nej w budynkach mieszkalnych według kryterium energetycznego z wykorzystaniem najistotniejszych zmiennych w zakresach spełniających aktualne wymagania.

\section{Optymalizacja wielkości otworów okiennych w literaturze naukowej}

Dwie publikacje, do których trzeba się odwołać, należą do autorów z Politechniki Wrocławskiej $[2,3]$. Opisali oni tok postępowania w obliczaniu udziału powierzchni okien w całkowitej powierzchni przegrody zewnętrznej. Ich prace są o tyle ciekawe, że wyliczenia przeprowadzają dla kompleksowego budynku, a podsumowują je tym, że mogą one stanowić poradnik dla projektantów-architektów podczas określania optymalnej powierzchni okien w projektowanych budynkach.

W pierwszym artykule poddanym analizie, napisanym jeszcze w 2010 roku przez M. Pomorskiego i S. Pietrowicza [2], autorzy już na wstępie deklarują, że ich obliczenia służyć będą zoptymalizowaniu powierzchni okien w taki sposób, by maksymalnie wykorzystać zyski cieplne pochodzące od promieniowania słonecznego. Próbując wykonać optymalizację powierzchni okien odwołują się do bilansu energetycznego dla całego budynku. Zatem poza zyskami zewnętrznymi, są również wzięte pod uwagę zyski wewnętrzne oraz straty przez przenikanie. Oczywiście wszystkie wyliczenia strat i zysków zostały zredukowane przez sprawność ich wykorzystania. Nie należy przeoczyć jednego stwierdzenia, które autorzy dodają pod koniec - zauważają oni, że są takie miesiące dla niektórych udziałów powierzchni szklonych w całych oknach, w których to zyski wielokrotnie przewyższają straty przez okna. Co zatem proponują autorzy? Należy, wg autorów, za wielkość zysków ciepła przez przenikanie przez przegrody szklone przyjąć wartość wyliczonych strat ciepła przez przenikanie. Można zadać pytanie czy opisana metoda jest doskonała? Na pewno należy ją przemyśleć. Przecież maksymalne zyski to nie to, czego należy szukać. Rozważyć należy taką sytuację, że dany rok (jak to ostatnimi czasy już bywało) jest wyjątkowy pod względem wysokości temperatury. Zima jest krótka i stosunkowo ciepła, a latem temperatury sięgają $35^{\circ} \mathrm{C}$. Czy wówczas również należy się nastawiać na maksymalizację zysków ciepła? Czy domownikom nie będą przeszkadzały wysoko przepuszczalne szyby w oknach i brak zacienia pomieszczeń przez całe lato? Na te pytania nie może być jednoznacznej odpowiedzi.. Zatem nie należy stawiać na jak najwyższe zyski cieplne za wszelką cenę. Jednak autorzy nie podjęli próby sprecyzowania jak chcą technicznie rozwiązać tę kwestię - zamiany zysków ciepła ze stratami w okresie letnim.

Kolejna publikacja, do jakiej należy nawiązać, jest autorstwa B. Zając i M. Pomorskiego [3]. Autorzy na początku swojej pracy odnoszą się do aktualnych przepisów prawnych odnośnie przegród przezroczystych w budynkach mieszkalnych. Najważniejszy wniosek, który z tego płynie jest taki, że jeśli współczynnik $U$ dla całkowitego okna jest niższy nić $0,9 \mathrm{~W} /\left(\mathrm{m}^{2} \mathrm{~K}\right)$, wówczas wielkość okien i ich ilość jest dowolna. Gdy ma on wyższą wartość, niestety należy dostosować się do obowiązujących norm. Następnie autorzy przedstawiają algorytm obliczenia energochłonności budynku. Ciekawe jest to o tyle, że obliczenia wykonywane są dla kilku orientacji, ale tylko dla jednej $\mathrm{z}$ nich zmianie ulega udział okna w przegrodzie. Wówczas autorzy wnioskują, że na wyniki energochłonności bardzo niekorzystnie wpływa zacienienie budynku, a udział okien, jaki został wyliczony, nie jest zgodny z przepisami. Na końcu, autorzy uznają że istnieje potrzeba wykonania obliczeń bilansu energetycznego stolarki okiennej uwzględniając zarówno parametry energetyczne okien, a także ich usytuowanie względem stron świata. 
Podsumowując można stwierdzić, że istnieje konieczność opracowania algorytmu obliczenia bilansu energetycznego, który szerzej i bardziej elastycznie uwzględniać będzie wpływ poszczególnych parametrów na końcowy wynik.

\section{Autorski algorytm obliczania bilansu energetycznego dla stolarki okiennej}

Bilans energetyczny stolarki okiennej w budynku mieszkalnym autorzy proponują opisywać wzorem:

$$
\Delta Q=Q_{t r, s, n, o}-Q_{s o l}+Q_{t r, s, n, s}[\mathrm{kWh} / \mathrm{m}-\mathrm{c}]
$$

gdzie: $Q_{t r, s, n, o}$ - straty przez przenikanie przez okna [kWh/m-c]; $Q_{s o l}$ - zyski słoneczne przez okna $[\mathrm{kWh} / \mathrm{m}-\mathrm{c}] ; Q_{t r, s, n, s}-$ straty przez przenikanie przez ścianę $[\mathrm{kWh} / \mathrm{m}-\mathrm{c}]$

Natomiast obliczenia składników bilansu energetycznego stolarki okiennej można przeprowadzić zgodnie z „Rozporządzeniem Ministra Infrastruktury z dn. 12 kwietnia 2002 r. W sprawie warunków technicznych jakim powinny odpowiadać budynki i ich usytuowanie z aktualizacją dnia 1 stycznia 2014 roku" [4], a także „Rozporządzeniem Ministra Infrastruktury w sprawie metodologii obliczania charakterystyki energetycznej budynku i lokalu mieszkalnego lub części budynku stanowiącej samodzielną całość techniczno-użytkową oraz sposobu sporządzania wzorów świadectw i ich charakterystyki energetycznej" [5].

Wtedy straty przez przenikanie można wyliczać ze wzoru:

$$
Q_{t r, s, n}=H_{t r, s} \cdot\left(\theta_{i n t, s, H}-\theta_{e, n}\right) \cdot t_{M} \cdot 10^{-3}[\mathrm{kWh} / \mathrm{m}-\mathrm{c}]
$$

gdzie: $H_{t r, s}$ - całkowity współczynnik przenoszenia ciepła przez przenikanie dla strefy ogrzewanej $[\mathrm{W} / \mathrm{K}] ; \theta_{\text {int,s,H }}$ - temperatura wewnętrzna dla okresu ogrzewania w budynku przyjmowana zgodnie $\mathrm{z}$ wymaganiami zawartymi $\mathrm{w}$ przepisach techniczno-budowlanych $\left[{ }^{\circ} \mathrm{C}\right] ; \theta_{e}-$ średnia temperatura powietrza zewnętrznego w analizowanym okresie miesięcznym wg danych dla najbliższej stacji meteorologicznej $\left[{ }^{\circ} \mathrm{C}\right]$;

Całkowity współczynnik przenoszenia ciepła przez przenikanie dla strefy ogrzewanej wyraża się wzorem:

$$
H_{t r, s}=\sum_{i}\left[b_{t r, i}\left(A_{i} U_{i}+\sum_{i} l_{i} \psi_{i}\right)\right][\mathrm{W} / \mathrm{K}]
$$

gdzie: $b_{t r, i}$ - współczynnik redukcyjny obliczeniowej różnicy temperatur; $A_{i}$ - pole powierzchni i-tej przegrody otaczającej przestrzeń ogrzewaną, obliczane wg wymiarów zewnętrznych; wymiary okien i drzwi przyjmuje się jako wymiary otworów w ścianie $\left[\mathrm{m}^{2}\right]$; $U_{i}$ - współczynnik przenikania ciepła i-tej przegrody pomiędzy przestrzenią ogrzewaną a otoczeniem zewnętrznym $\left[\mathrm{W} / \mathrm{m}^{2} \mathrm{~K}\right] ; \psi_{i}$ - liniowy współczynnik przenikania ciepła mostka cieplnego [W/mK], przyjęty wg normy PN-EN ISO 14683:2008[6] ;

Całkowita ilość ciepła przenoszonego ze strefy ogrzewanej przez przenikanie wyraża się wzorem:

$$
Q_{t r, s, n}=\sum_{i}\left[b_{t r, i}\left(A_{i} U_{i}+\sum_{i} l_{i} \psi_{i}\right)\right] \cdot\left(\theta_{i n t, s, H}-\theta_{e, n}\right) \cdot t_{M} \cdot 10^{-3} \quad[\mathrm{kWh} / \mathrm{m}-\mathrm{c}]
$$

Zyski ciepła od promieniowania słonecznego wyrażają się wzorem: 


$$
Q_{s o l, H}=\sum_{i} C_{i} \cdot A_{i} \cdot I_{i} \cdot F_{s h} \cdot F_{s h, g l} \cdot g_{g l}[\mathrm{kWh} / \mathrm{m}-\mathrm{c}]
$$

gdzie: $C_{i}$ - udział pola powierzchni płaszczyzny szklonej do całkowitego pola powierzchni okna, jest zależny od wielkości i konstrukcji okna; $A_{i}$ - pole powierzchni okna lub drzwi balkonowych w świetle otworu w przegrodzie $\left[\mathrm{m}^{2}\right] ; I_{j}$ - wartość energii promieniowania słonecznego w rozpatrywanym miesiącu na płaszczyznę, w której usytuowane jest okno o powierzchni $A_{i}$, wg danych dotyczących najbliższego punktu pomiarów promieniowania słonecznego $\left[\mathrm{kWh} / \mathrm{m}^{2} \mathrm{~m}-\mathrm{c}\right] ; F_{s h}$ - czynnik redukcyjny ze względu na zacienienie od przegród zewnętrznych; $F_{s h, g l}$ - czynnik redukcyjny ze względu na zacienienie dla ruchomych urządzeń zacieniających; $g_{g l}$ - całkowita przepuszczalność energii promieniowania słonecznego dla przezroczystej części okna, drzwi balkonowych lub powierzchni oszklonej;

Obliczenie współczynnika przenikania ciepła U dla okien można wykonywać wg PNEN ISO 10077-1:2007, Cieplne właściwości użytkowe okien, drzwi i żaluzji. Obliczanie współczynnika przenikania ciepła. Część 1: Metoda uproszczona [7]:

$$
U_{w}=\frac{A_{g} U_{g}+A_{f} U_{f}+l_{g} \psi_{g}}{A_{g}+A_{f}} \quad\left[\mathrm{~W} / \mathrm{m}^{2} \mathrm{~K}\right]
$$

gdzie: $U_{w}$ - średni współczynnik przenikania ciepła okna $\left[\mathrm{W} / \mathrm{m}^{2} \mathrm{~K}\right] ; U_{f}-$ współczynnik przenikania ciepła ramy $\left[\mathrm{W} / \mathrm{m}^{2} \mathrm{~K}\right] ; U_{g}$ - średni współczynnik przenikania ciepła szyby $\left[\mathrm{W} / \mathrm{m}^{2} \mathrm{~K}\right] ; \psi_{g}$ - liniowy współczynnik przenikania ciepła mostka cieplnego na styku szyby z ramą okna $[\mathrm{W} / \mathrm{mK}]$, przyjęty wg $[6] ; A_{f}$ - pole powierzchni ramy o współczynniku $U_{f}\left[\mathrm{~m}^{2}\right] ; A_{g}-$ pole powierzchni szyby $\left[\mathrm{m}^{2}\right] ; l_{g}-$ dhugość liniowego mostka cieplnego na styku szyby z ramą $[\mathrm{m}] ; A_{0}=A_{g}+A_{f}-$ powierzchnia całkowita okna $\left[\mathrm{m}^{2}\right]$;

Analizując powyższe wzory, autorzy stwierdzili, że jedynie niewielka grupa zmiennych, które są sterowalne, mierzalne, wzajemnie niezależne, niesprzeczne i jednoznaczne, mogą pozwolić, przy odpowiednim wyborze ich wartości, dobierać w sposób skuteczny i oczywisty optymalne rozwiązanie stolarki okiennej według kryterium minimalnej wartości bilansu cieplnego. To są: 1 - pole powierzchni okna $A_{0} ; 2$ - udział pola powierzchni płaszczyzny szklonej do całkowitego pola powierzchni okna $C ; 3$ - średni współczynnik przenikania ciepła szyby $U_{g} ; 4$ - współczynnik przenikania ciepła ramy $U_{f} ; 5$ - całkowita przepuszczalność energii promieniowania słonecznego dla przezroczystej części okna $g$. Te zmienne zostały przyjęte przez autorów do opracowania modelu matematycznego bilansu energetycznego okien.

Na rys. 1 został przedstawiony schemat blokowy obliczenia bilansu energetycznego okien w budynkach mieszkalnych. Zaproponowany powyżej schemat obliczeń i program badawczy pozwalają w łatwy sposób realizować eksperyment obliczeniowy dla opracowania modeli matematycznych bilansu energetycznego stolarki okiennej dla różnych warunków brzegowych, dzięki którym to można określić parametry optymalne. 


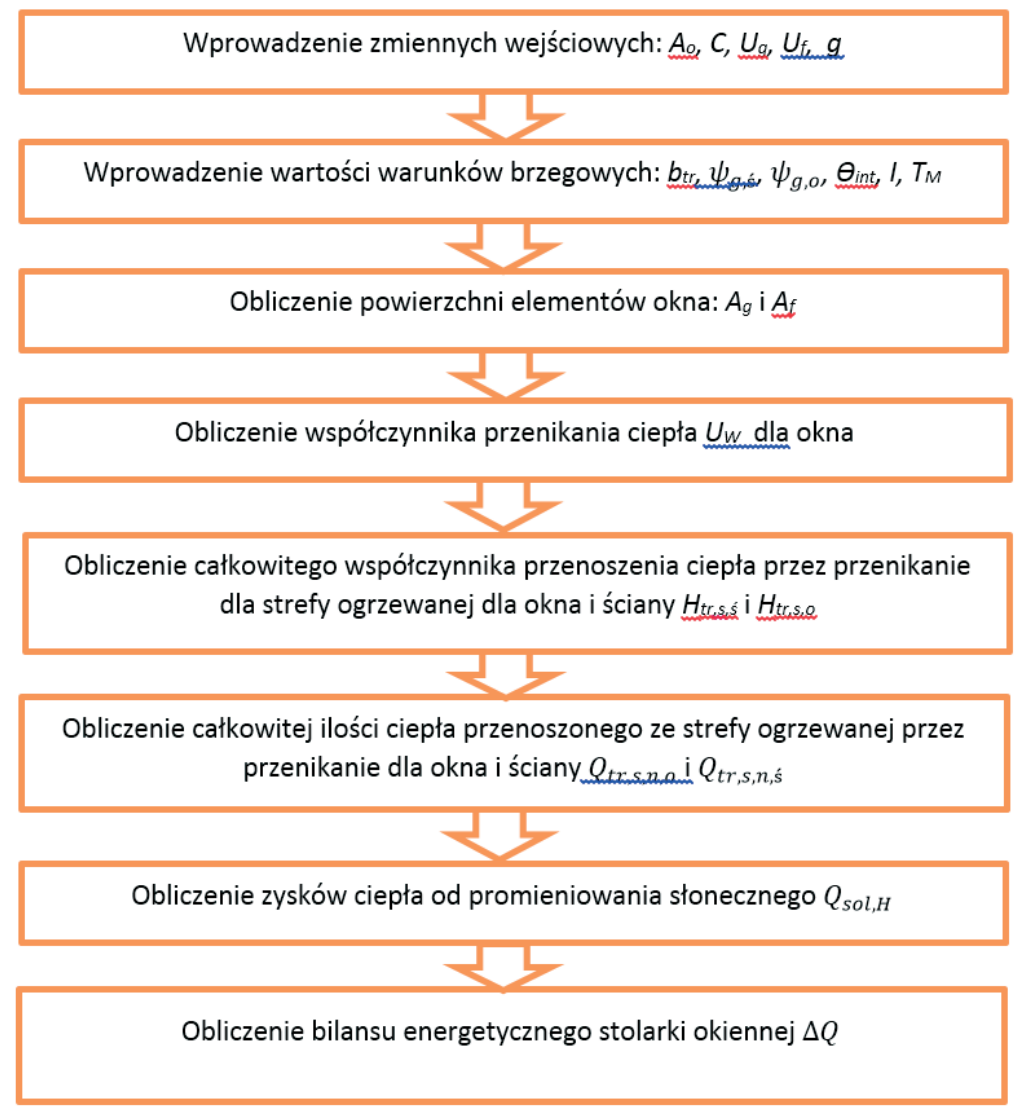

Rys.1. Schemat blokowy toku postępowania przy obliczaniu bilansu energetycznego stolarki okiennej [opracowanie własne na podstawie [5]]

\section{Planowanie eksperymentu obliczeniowego}

Opisane w literaturze próby zoptymalizowania parametrów cieplnych stolarki okiennej w budynkach mieszkalnych nie były jednoznaczne i kompletne, dlatego też zaistniała potrzeba stworzenia nowego, autorskiego podejścia do opracowania modelu matematycznego na podstawie planu eksperymentu obliczeniowego, który w sposób bezpośredni i właściwy mógłby rozwiązać ten problem.

Bilans energetyczny $\Delta Q(Y)$ w tym przypadku stanowić będzie suma start i zysków ciepła dla badanego fragmentu przegrody z uwzględnieniem faktu czy ciepło przepływa przez okno, czy też przez ścianę (wzór 1).

Oznaczamy zmienne niezależne jako czynniki $X_{1}, X_{2}, X_{3}, X_{4}, X_{5}$ funkcji celu $Y$ :

$X_{1}=A$ - powierzchnia okna, wyrażona $\mathrm{w}\left[\mathrm{m}^{2}\right]$;

$X_{2}=C$ - udział pola powierzchni płaszczyzny szklonej do całkowitego pola powierzchni okna, jest zależny od wielkości i konstrukcji okna, wyrażony w [\%];

$X_{3}=U_{g}-$ średni współczynnik przenikania ciepła szyby, wyrażony $\mathrm{w}\left[\mathrm{W} / \mathrm{m}^{2} \mathrm{~K}\right]$;

$X_{4}=U_{f}-$ współczynnik przenikania ciepła ramy, wyrażony w $\left[\mathrm{W} / \mathrm{m}^{2} \mathrm{~K}\right]$;

$X_{5}=g_{g l}$ - całkowita przepuszczalność energii promieniowania słonecznego dla przezroczystej części okna, wyrażona w [\%]. 
Określono właściwe warunki brzegowe dla pozostałych zmiennych oraz konkretne wielkości stałe:

- współczynnik redukcyjny obliczeniowej różnicy temperatur $b_{t r}$,

- liniowy współczynnik przenikania ciepła mostka cieplnego dla okna,

- liniowy współczynnik przenikania ciepła mostka cieplnego dla ściany,

- $\Theta_{\text {int }}$ - temperatura powietrza wewnętrznego okresu ogrzewania,

- I-średnie miesięczne natężenie promieniowania słonecznego,

$-t_{M}-$ liczba godzin w miesiącu.

Zgodnie z założonym celem badania oraz wybraną postacią funkcji (wielomian drugiego stopnia), do realizacji eksperymentu obliczeniowego dobrano plan kompozycyjny symetryczny $\mathrm{B}_{5}$ (tabela 1) [8]. Plan ten należy do grupy planów statystycznych, zdeterminowanych, poliselekcyjnych. W dobranym planie $\mathrm{B}_{5}$ liczba układów planu wynosi 26, w których umieszczono zakodowane wartości.

W planach eksperymentów stosowane są wartości unormowane czynników zamiast naturalnych wartości ilościowych. Przejście z wartości naturalnych do unormowanych wyraża się wzorem (7):

$$
X_{i}=\frac{\tilde{X}_{i}-\frac{\tilde{X}_{i \max }+\tilde{X}_{i \min }}{2}}{\frac{\tilde{X}_{i \max }-\tilde{X}_{i \min }}{2}}
$$

gdzie: $X_{i}, X_{\text {imax }}, X_{\text {imin }}$ odpowiednio bieżące, maksymalne i minimalne wartości naturalne i-tego czynnika.

Tabela 1. Plan kompozycyjny symetryczny B 5 [8]

\begin{tabular}{ccccccc}
\hline $\mathrm{Nr}$ & $X_{1}\left(A_{0}\right)$ & $X_{2}(C)$ & $X_{3}(U g)$ & $X_{4}\left(U_{f}\right)$ & $X_{5}(g)$ & $Y(D Q)$ \\
\hline 1. & -1 & -1 & -1 & -1 & 1 & \\
2. & 1 & -1 & -1 & -1 & -1 & \\
3. & -1 & 1 & -1 & -1 & -1 & \\
$4-23$ & $\ldots$ & $\ldots$ & $\ldots$ & $\ldots$ & $\ldots$ & \\
24. & 0 & 0 & 0 & 1 & 0 & \\
25. & 0 & 0 & 0 & 0 & -1 & \\
26. & 0 & 0 & 0 & 0 & 1 & \\
\hline
\end{tabular}

Po przeliczeniu wartości kodowanych czynników na rzeczywiste, należy je umieścić w odpowiednich rubrykach planu roboczego. Dopiero tak przygotowany plan eksperymentu stanowi podstawę do wykonania obliczeń funkcji celu $Y$. Opracowany wektor $Y$ razem z planem tworzy możliwość do opracowania modelu matematycznego zależności $Y=$ $\mathrm{f}\left(X_{1}, X_{2}, X_{3}, X_{4}, X_{5}\right)$, który może być podstawą do przeprowadzenia optymalizacji.

\section{Podsumowanie}

1. Opisane w literaturze naukowej próby optymalizacji parametrów energetycznych stolarki okiennej różniły się między sobą zarówno uwzględnionymi zmiennymi jak i metodami wykorzystanymi do sporządzenia bilansu energetycznego. Jednakże żadna z nich nie była doskonała i dlatego istnieje konieczność przeprowadzenia dalszych badań w kierunku optymalizacji parametrów okien według kryterium energetycznego. 
2. Przedstawiony algorytm obliczania bilansu energetycznego stolarki okiennej uwzględnia składniki strat i zysków ciepła, wpływ mostków cieplnych na styku rama szklenie oraz rama - ściana. Nie pomija także unikatowej wartości współczynników przenikania ciepła $U$ oddzielnie dla szyby i dla ramy oraz przepuszczalności energii słonecznej przez szybę.

3. Wyodrębnione z przedstawionego algorytmu obliczania bilansu energetycznego okien najistotniejsze zmienne, przyjęte jako czynniki, pozwolą poprzez realizację planu eksperymentu obliczeniowego opracować zależności funkcji celu $Y$ od wybranych czynników dla różnych warunków brzegowych. Uzyskane zależności stworzą podstawę do przeprowadzenia uzasadnionej optymalizacji parametrów stolarki okiennej.

4. Wyniki badań według zaproponowanego algorytmu pozwolą uzyskać odpowiedź na liczne pytania dotyczące wyboru parametrów stolarki okiennej oraz mogą być bardzo przydatne w praktycznym projektowaniu architektoniczno-budowlanym.

\section{Literatura}

1. Kasperkiewicz K., Jakość energetyczna okien - wymagania, metody oceny i aktualne możliwości techniczne. Materiały Budowlane 8 (2006) 53-56.

2. Pomorski M., Pietrowicz S., Określanie optymalnego udziału powierzchni przegrody przezroczystej $w$ całkowitej powierzchni przegrody budowlanej, Polska Energetyka Słoneczna, 2-4 (2010) 12-16.

3. Zając B., Pomorski M., Określanie optymalnego udziału okien w budynku mieszkalnym, Zeszyty naukowe Politechniki Rzeszowskiej, lipiec-wrzesień (2015) 269-276.

4. Rozporządzenie Ministra Infrastruktury z dn. 12 kwietnia 2002 r. w sprawie warunków technicznych jakim powinny odpowiadać budynki i ich usytuowanie z późniejszymi aktualizacjami.

5. Rozporządzenie Ministra Infrastruktury w sprawie metodologii obliczania charakterystyki energetycznej budynku i lokalu mieszkalnego lub części budynku stanowiącej samodzielną całość techniczno-użytkową oraz sposobu sporządzania wzorów świadectw i ich charakterystyki energetycznej.

6. PN-EN ISO 14683:2008, Mostki cieplne w budynkach. Liniowy współczynnik przenikania ciepła. Metody uproszczone i wartości orientacyjne.

7. PN-EN ISO 10077-1:2007, Cieplne właściwości użytkowe okien, drzwi i żaluzji. Obliczanie współczynnika przenikania ciepła. Część 1: Metoda uproszczona.

8. Polański Z., Planowanie doświadczeń w technice. Wyd. PWN, 1984.

\section{The mathematical model of energy balance for windows in residential buildings}

\section{Joanna Borowska, Walery Jezierski}

Department of Basic Building Construction and Building Physics, Faculty of Civil and Environmental Engineering, Bialystok University of Technology, e-mail:j.borowska@doktoranci.pb.edu.pl,w.jezierski@pb.edu.pl

\footnotetext{
Abstract: The paper presents a developed mathematical model, made by the authors, which is used to calculate the energy balance of windows in residential buildings. There is presented an algorithm for calculating the components of loss and heat gain of the energy balance of the window, as well as the course of action while choosing variable parameters,
} 
which are the part of mathematical model and also are suitable to make the optimisation of windows, like: the window surface, heat-transfer coefficients $U$ for the glass and the window frame, the permeability factor $g$ and others. There is also suggested the programme of a calculation experiment.

Keywords: the energy balance, window joinery, a mathematical model. 